\title{
Emergence of behavioral primitives in self-organizing control and composition of behavior for autonomous robots Georg Martius*1,2 and J Michael Herrmann1,2,3
}

\author{
Address: ${ }^{1}$ Max Planck Inst. for Dynamics and Self-Organization, Dept. of Nonlinear Dynamics, 37073 Göttingen, Germany, ${ }^{2}$ Bernstein Center for \\ Computational Neuroscience, 37073 Göttingen, Germany and ${ }^{3}$ University of Edinburgh, School of Informatics, IPAB, 10 Crichton St., Edinburgh \\ EH8 9AB, UK \\ Email: Georg Martius* - georg@nld.ds.mpg.de \\ * Corresponding author
}

from Eighteenth Annual Computational Neuroscience Meeting: CNS*2009

Berlin, Germany. 18-23 July 2009

Published: 13 July 2009

BMC Neuroscience 2009, I0(Suppl I):OI doi:I0.II86/I47I-2202-I0-SI-OI

This abstract is available from: http://www.biomedcentral.com/I47I-2202/I0/SI/O I

(c) 2009 Martius and Herrmann; licensee BioMed Central Ltd.

\section{Background}

Autonomous robots as well as animals process sensory information for the purpose of generating behaviors that are adapted to their respective environments. This includes the selection of behaviorally relevant perceptual features, the adaptation of control mechanisms and the storage and the recall of behavioral episodes for planning and execution. A robot as model of animal behavior should achieve sensorimotor control without being specifically programmed, but by exploring the behaviors that arise from the physical interaction between its body and the environment.

\section{Self-organizing behavior}

Efficient behavioral exploration can be obtained by the homeokinetic principle [1], a dynamical systems approach to robot control that establishes a self-tuned balance between sensitivity of actions to sensory inputs and predictability of the perceptual consequences of actions. The principle is effective in training artificial motor neurons to generate coherent movements that are suitable to explore the behavioral manifold [2]. Simultaneously, internal representations of the robot dynamics are learned by associative memory networks in the robot, which then play the role of an efference copy.

\section{Composing behavioral primitives}

In the present contribution we introduce an agent-based approach where a number of internal expert networks compete for the correct prediction of the control actions of a homeokinetic controller. As a result each agent achieves control over a specific reproducible behavior that forms a behavioral primitive. The obtained collection of behaviors is specific for the robot and the environment, but the elementary behaviors can be selected and combined to control the robot successful also in new environments. The composition of behaviors is achieved by a

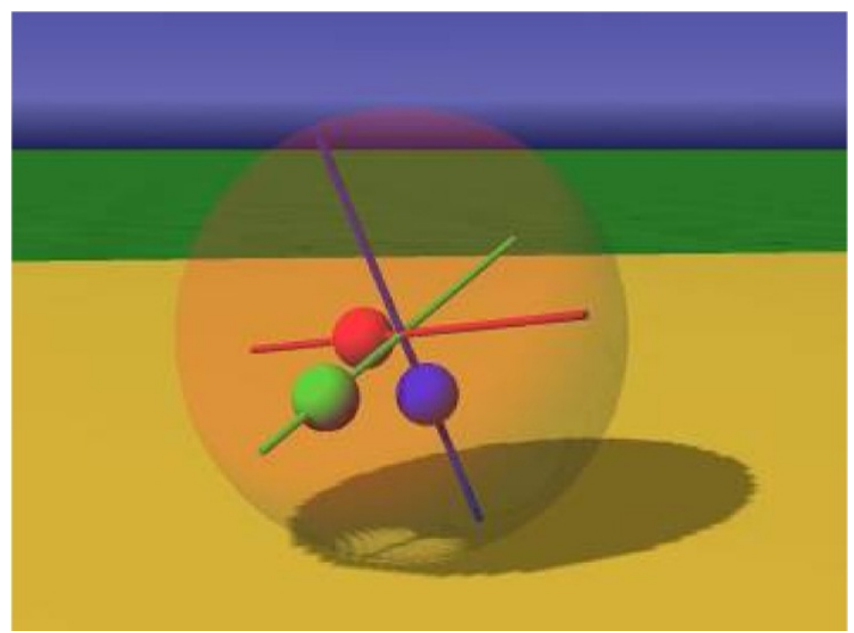

Figure I

Simulated spherical robot actuated by three internal masses that are moveable along their axes. 


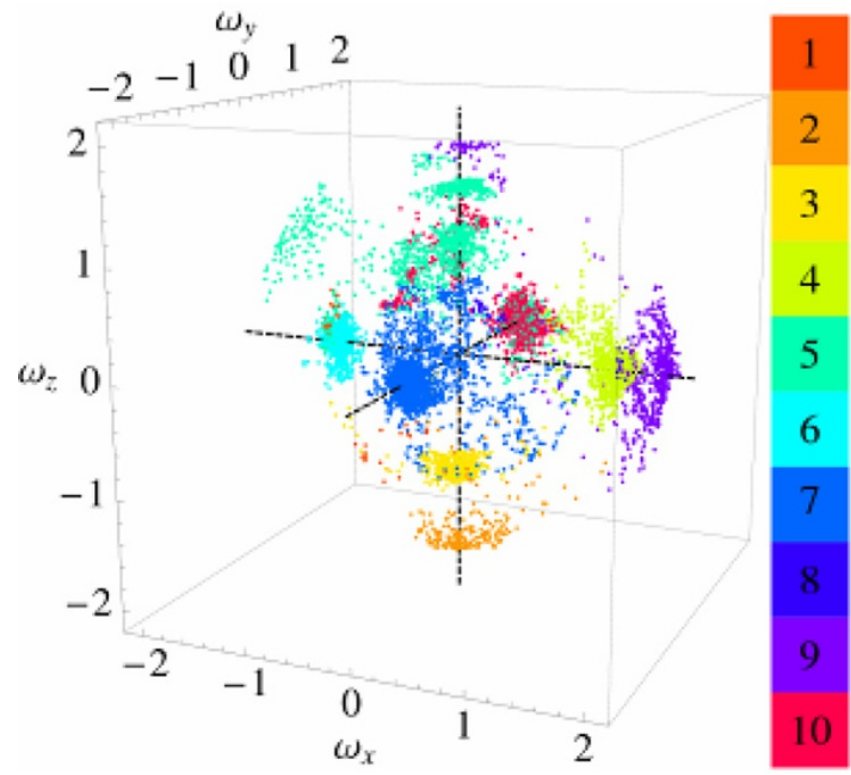

Figure 2

Partition of the space of angular velocities of the spherical robot by a set of control agents.

standard reinforcement learning algorithm with intrinsically determined rewards. The composition of the primitives is shown to be efficient for set of experts, but cannot be achieved when low-level actions used as elements. Videos of various robots (Figure 1) illustrate the study that also includes different degrees of specificity of the internal representations (Figure 2) and comparisons with classical methods.

In conclusion, exploration of behavioral spaces by selforganizing control leads to the emergence of behavioral primitives that can be composed in order to generate complex goal-oriented behavior and can be used in motor planning.

\section{Acknowledgment}

The project was supported by the BCCN Göttingen grant \#01GQ0432.

\section{References}

I. Der R: Self-organized acquisition of situated behavior. Theory in Biosciences 200I, I 20:179-187.

2. Der R, Hesse F, Martius G: Rocking stamper and jumping snake from a dynamical system approach to artificial life. Adaptive Behavior 2006, 14:105-1 I5 [http://robot.informatik.uni-leipzig.de].
Publish with Biomed Central and every scientist can read your work free of charge

"BioMed Central will be the most significant development for disseminating the results of biomedical research in our lifetime. " Sir Paul Nurse, Cancer Research UK

Your research papers will be:

- available free of charge to the entire biomedical community

- peer reviewed and published immediately upon acceptance

- cited in PubMed and archived on PubMed Central

- yours - you keep the copyright

Submit your manuscript here:

http://www.biomedcentral.com/info/publishing_adv.asp 